\title{
Neurological complications of progressive facial hemiatrophy
}

\author{
SHELDON MARK WOLF ${ }^{1}$ AND M. ANTHONY VERITY \\ From the Departments of Neurology, Southern California Permanente Medical Group \\ and the University of Southern California Medical School, and the Department of Pathology \\ (Neuropathology), Center for the Health Sciences, UCLA, Los Angeles, California, U.S.A.
}

SYNOPSIS Progressive left facial hemiatrophy began in a boy at the age of 5 years. Over the next 20 years, he developed wasting of the left shoulder and arm muscles, ptosis of the eyelids, ophthalmoplegia, convergence nystagmus, pupillary dilatation, hemiparesis, seizures, and dysarthria. A pneumoencephalogram showed cerebellar hemiatrophy. Biopsy of the cerebellum revealed loss of and degenerative changes in Purkinje cells. A deltoid muscle biopsy studied by histochemical and enzymatic procedures was normal. There are many neurological and ophthalmological complications of progressive facial hemiatrophy. Seizures, ophthalmoparesis, and pupillary abnormalities are the most common. The aetiology and pathogenesis of the disease are unknown. The possibility that this is a 'slow virus' disease is suggested.

Facial hemiatrophy is a rare disease characterized by wasting of the skin and subcutaneous tissue of the face. Muscle, cartilage, and bone may also be involved. The onset is insidious, usually in the first two decades, and the course slowly progressive. Progression may stop at any point, leaving variable degrees of deformity. The atrophy is almost always unilateral but occasionally bilateral. The disease is much more widespread than its name would indicate, and may involve extremities, larynx, pharynx, eyes, brain, and other organs. The purpose of this paper is to present a case with the hitherto unreported complication of cerebellar atrophy which also showed an extraordinary sequence of neurological and ophthalmological abnormalities, and in which brain and muscle biopsies were studied.

\section{CASE REPORT}

A 26 year old male was first noted to have loss of hair and subcutaneous tissue over the left temple at the age of 5 years (Fig. 1). At age 6 years (Fig. 2) he developed ptosis of the right eyelid, and atrophy of the left pectoral and platysma muscles. A neostig-

1 Address for reprints: Dr Wolf, 1526 North Edgemont Street, Los Angeles, California 90027, U.S.A. mine test was negative. At age 11 years, there was an irregular depression of the scalp over the left hemicranium. There was atrophy of the left sterno-

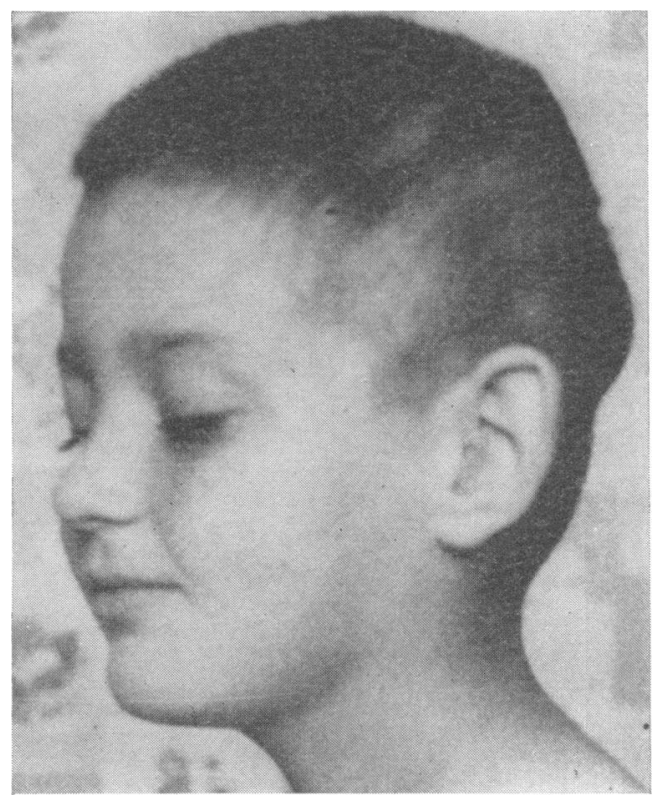

FIG. 1. Child, aged 5 years, with unilateral hair loss. 


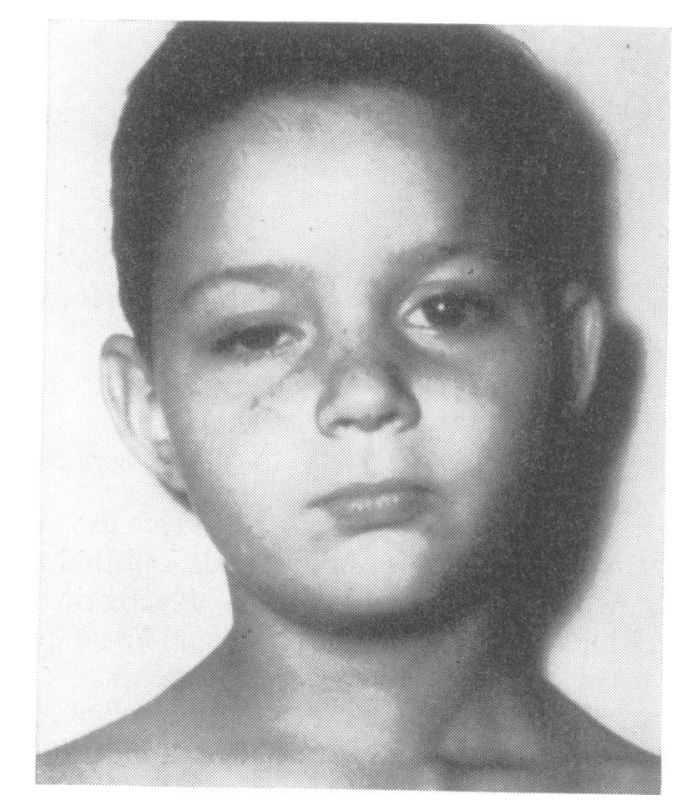

FIG. 2. Child, aged 6 years, with ptosis of right upper eyelid.

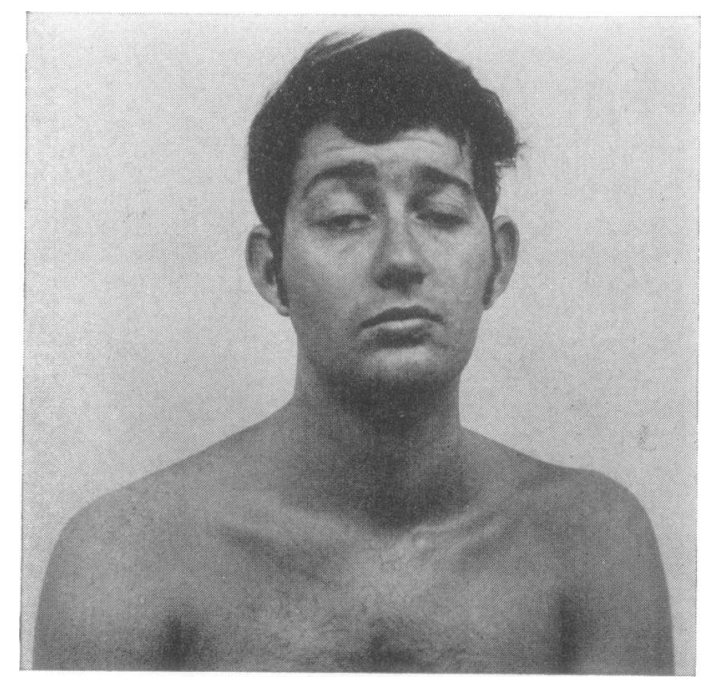

FIG. 3. Patient, aged 23 years, with bilateral eyelid ptosis and atrophy of left trapezius muscle. cleidomastoid muscle. The ptosis was bilatera: Extraocular movements were full. The left arm wa smaller than the right. An electroencephalogran showed a focus of 3 to $5 \mathrm{~Hz}$ slow activity over the left parietal area. Examination in 1964, at age 19 years, showed bilateral ptosis of the eyelids, now worsened by repeated forceful blinking. Both pupis. were of equal size. There was a left gaze paresis and weakness of the left superior rectus muscle. Otheo extraocular movements were normal. At age 28 years, in 1970, he suffered two major motor seizures preceded by an aura of repetitively flashing lights i front of him. The left trapezius and forearm muscles were noted to be smaller than on the right (Fig. 3) Sustained nystagmus was noted on convergenceWhen he looked upward, the left eye showed an intermittent clockwise rotary nystagmus. Downgaz $\overrightarrow{e_{b}}$ was normal. On conjugate lateral gaze to the right? the left upper eyelid drooped noticeably with almos total obliteration of the palpebral aperture. On gaz to the left, the palpebral fissure widened to its usuat size. Visual fields, opticokinetic responses, and corneal sensitivity were normal.

Normal or negative laboratory tests includeo complete blood count, urinalysis, fasting blo sugar, serum calcium, VDRL and fluorescents treponemal antibody; skull films, brain scan, cexe brospinal fluid examination, and serum enzyrgesD were also normal. Electromyography showed, in left frontalis and temporalis muscles, large numberts of very small, short duration motor unit potentiäts $\overrightarrow{0}$ suggestive of myopathy. Pneumoencephalography showed minimal rounding of the superior latera $b$ angles of the anterior horn of the lateral ventricles, suggesting minimal cerebral atrophy, and slight deviation of the fourth ventricle to the left.

In August 1972, his speech gradually becameू slurred. There was no vertigo or ataxia. Phenytoin? was discontinued and phenobarbitone, $60 \mathrm{mg}$ daily, $\overrightarrow{\overrightarrow{0}}$ was substituted, without improvement of the dys 3 arthria. He noted increasing clumsiness and poor coordination of the right hand.

In October 1972, examination showed for the first time a dilated left pupil which did not react directlyo or consensually to light. The right pupil was of normal size and reacted well to light, both directly? and consensually. Only the right pupil reacted too accommodation. The visual acuity, visual fields, and $₹$ optic fundi were normal. Extraocular movementso were as previously described. Corneal reflexes were normal. There was a right hemiparesis including the을. face. Speech was very slurred and dysarthric. Palatal and lingual movements and the gag reflex were 5 normal. Sensation to pin prick and touch were re- $N$ duced over the right face and body. Heel along shin and finger to nose movements were normal. Bi-O 


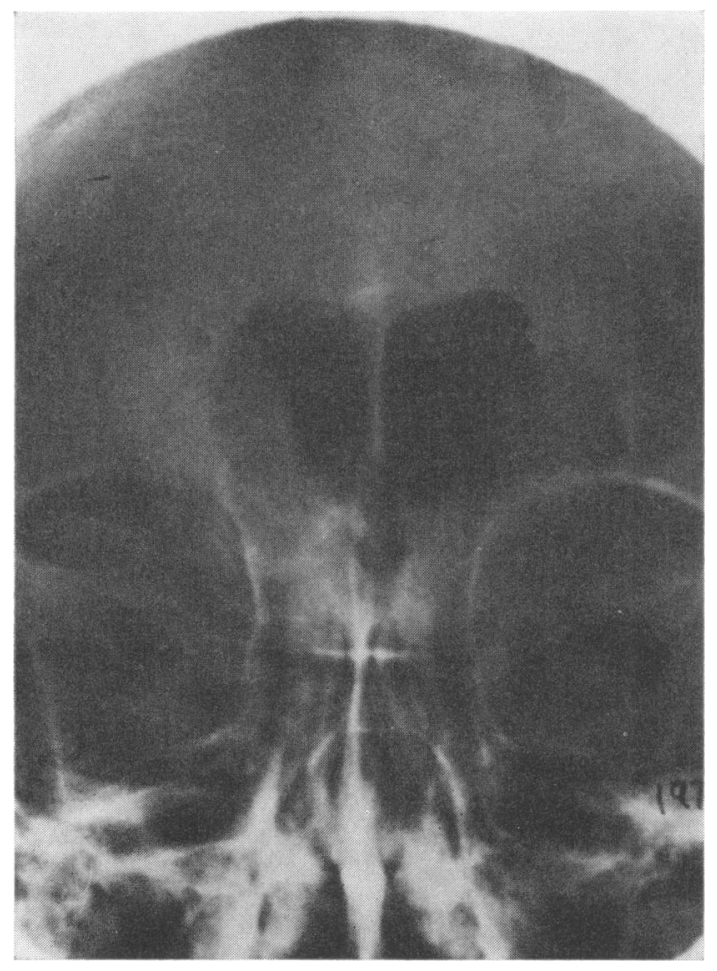

FIG. 4. Pneumoencephalogram showing bilateral ventricular enlargement.

lateral carotid and vertebral angiograms were normal. Pneumoencephalography (Figs 4 and 5) now showed diffuse, moderate enlargement of the entire ventricular system. Since the previous pneumoencephalogram two years before, the fourth ventricle had become further deviated to the left. The posterior fossa cisterns were enlarged. There was no evidence of a mass lesion. The sequence of pneumoencephalograms was interpreted as showing progressive atrophy of the left side of the cerebellum causing ipsilateral deviation of the fourth ventricle, and progressive generalized hydrocephalus ex vacuo.

Serum protein electrophoresis and levels of immunoglobulin $G$, immunoglobulin $A$, and immunoglobulin $\mathbf{M}$ were normal. A radiograph of the chest showed strand densities and pleural thickening in the left upper lung field with slight tracheal shift to the left, suggesting retraction and scarring from old, inflammatory disease.

In January 1973, left frontal and cerebellar brain biopsies and a biopsy of the left deltoid muscle were

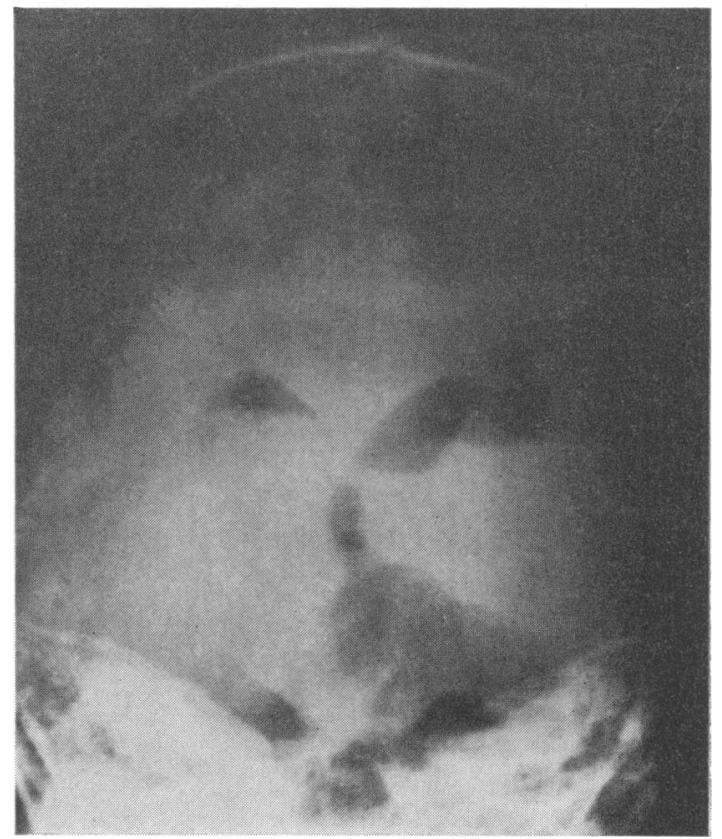

FIG. 5. Pneumoencephalogram showing deviation of the fourth ventricle to the left and enlargement of the posterior fossa cisterns.

performed. The left frontal lobe appeared grossly normal. The left cerebellar hemisphere appeared atrophic.

PATHOLOGICAL FINDINGS Tissue from the cerebrum and cerebellum was processed for routine light $(\mathrm{H}$ and E, Wiel, Klüver, periodic acid-Schiff) and electron microscopic evaluation, biochemistry, and viral inoculation studies. The muscle biopsy specimen was processed for histochemical and histoenzymatic studies on cryostat sections.

The left deltoid muscle biopsy was normal. No disturbance of the fascicular architecture was evident. The endomysial connective tissue and vascularity appeared unremarkable and normal in amount. Gomori trichrome reactions, myofibrillar ATPase, and mitochondrial oxidative reactions (succinic dehydrogenase and NADH dehydrogenase) were entirely normal and revealed a normal complement and disposition of type I and type II muscle fibres. Phosphorylase was present. 


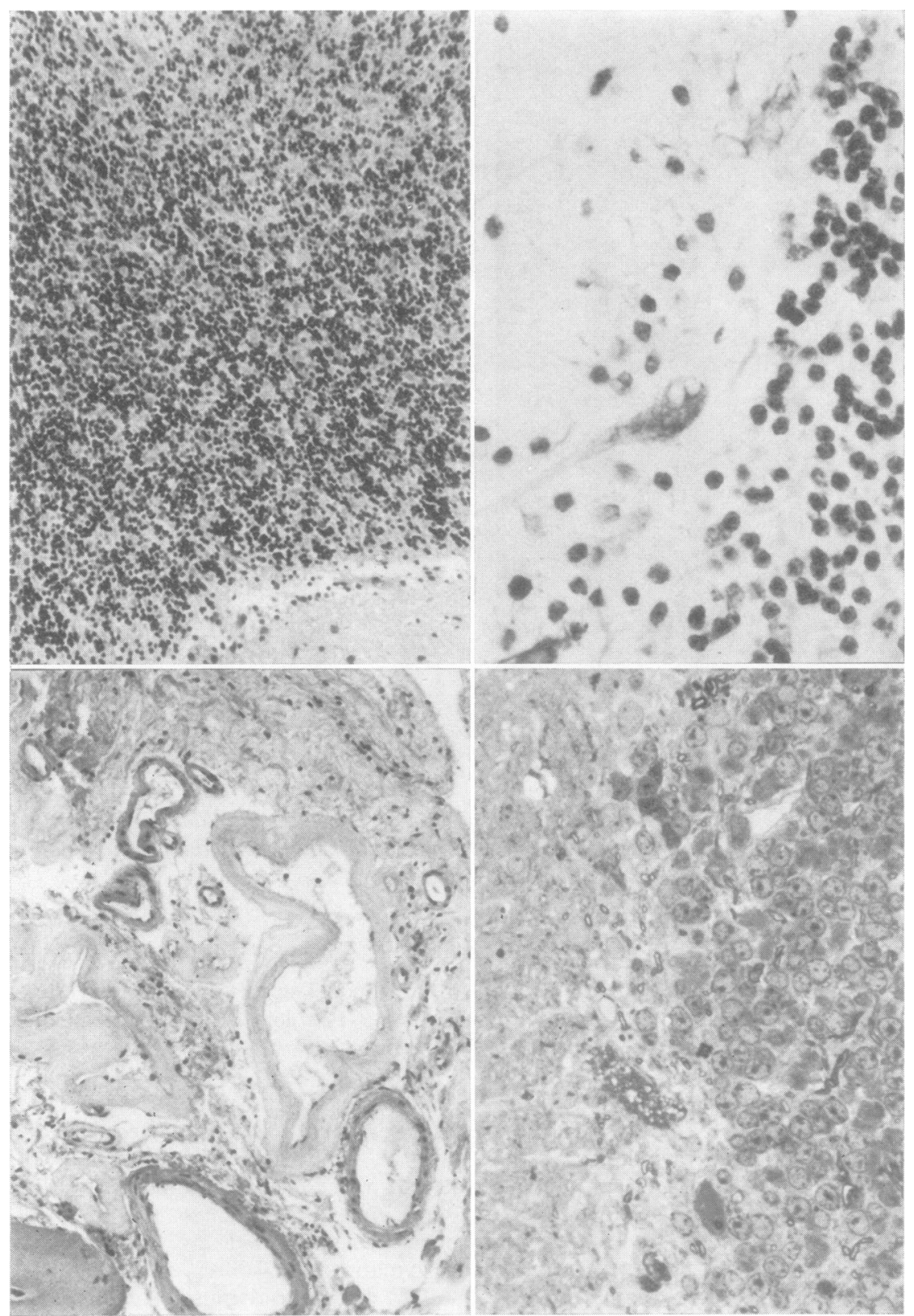

FIG. 6. (Top left). Coronal section of cerebellum showing mild patchy rarefaction of granular layer, loss of Purkinje cells and mild Bergman gliosis. $H$ and $E, \times 110$. FIG. 7. (Top right). Degenerative and vacuolar changes are evident in the perikarya of the Purkinje cells. Klüver, $\times 450$. FIG. 8. (Bottom left). Small angiomatous malformation in leptomeninges of cerebellar folium. Mural hyalinization and increased leptomeningeal fibrosis is noted. $H$ and $E, \times 110$. FIG. 9. (Bottom right). Eponembedded $1 \mu \mathrm{m}$ section showing loss and microscopic vesiculation of remaining Purkinje cell. Increased nucleation in Purkinje layer is consistent with gliosis. Toluidine blue, $\times 450$. 
The cerebral cortex contained a normal population of neurones and the cortical laminae were preserved. A few dark neurones were seen. There was no evidence of meningeal fibrosis or inflammation. Minimal non-diagnostic changes, including rare neuronal satellitosis and minimal rarefaction of the subcortical white matter, were seen. Two small cortical arteries were surrounded by a few nonspecific mononuclear cells. The cerebellar biopsy was abnormal. There was striking Purkinje cell loss (Fig. 6) and the remaining Purkinje cells revealed degenerative changes, including nuclear pyknosis, cytoplasmic angulation and vacuolar changes of the cytoplasm extending into the axon hillock (Fig. 7). Also observed was mild, patchy rarefaction of the granular layer and mild atrophy of the molecular layer containing rare 'torpedo changes' in some axons. A small leash of tortuous, medium-sized blood vessels was present in the leptomeninges of one cerebellar folium (Fig. 8). Degenerative and hyalinizing changes in their walls and partial obliteration of the lumen was noted, suggestive of a microscopic vascular malformation. Calcification was not detected. One micron section embedded in Epon confirmed the cytoplasmic vacuolar change of the Purkinje cells (Fig. 9).

No viral inclusions or C-particles were identified in survey electron micrographs of cortex and cerebellum. Ganglioside chromatography of the cerebral biopsy showed that $\mathrm{g} 3$ was reduced. Neutral lipids appeared normal, as did the phospholipids, but there was an increase in lactosyl ceramide and trihexosyl ceramide.

\section{DISCUSSION}

Tables 1 and 2 list the neurological and ophthalmological abnormalities which have been reported in progressive facial hemiatrophy. The most common neurological complication is seizures (Wartenberg, 1925; Archambault and Fromm, 1932; Merritt et al., 1937; Wartenberg, 1945; Eadie et al., 1963; Moura, 1963; Brain and Walton, 1969; Walsh and Hoyt, 1969). These may be generalized major motor, focal motor or sensory. The focal seizures are usually on the side opposite the facial atrophy.

A wide variety of ophthalmological abnormalities has been described, most often ophthalmoparesis and pupillary abnormalities (Archambault and Fromm, 1932; Merritt et al., 1937; Walsh, 1939; Moura, 1963; Banks and Sugar, 1963; Rogers, 1964; Sugar and Banks, 1964;
TABLE 1

NEUROLOGICAL COMPLICATIONS OF PROGRESSIVE FACIAL HEMIATROPHY

\begin{tabular}{ll}
\hline & Neurological complications \\
\hline Seizures & Hemianopia \\
Facial palsy & Aphasia \\
Facial neuralgia & Migraine headaches \\
Hemiplegia & Impairment of sweating \\
Hemianaesthesia & Ventricular dilatation \\
\hline
\end{tabular}

TABLE 2

OPHTHALMOLOGICAL ABNORMALITIES IN PROGRESSIVE FACIAL HEMIATROPHY

\begin{tabular}{ll}
\hline \multicolumn{2}{c}{ Ophthalmological abnormalities } \\
\hline Ptosis & Argyll-Robertson pupil \\
Weakness of extraocular muscles & Blepharophimosis \\
Enophthalmos & Uveitis \\
Horner's syndrome & Keratitis \\
Miosis & Vitreous haemorrhage \\
Mydriasis & Choreoretinitis \\
Heterochromia of iris & Chorioiditis \\
Heterochromic cyclitis & Cataract \\
Corneal ulceration & Exophthalmos \\
Optic neuritis & Iris atrophy \\
Optic atrophy & \\
\hline
\end{tabular}

Dawson and Beare, 1966; Johnson and Kennedy, 1969).

Pneumoencephalograms have often, as in our patient, shown dilatation of one or both lateral ventricles. Unilateral dilatation of a lateral ventricle has been described both ipsi- and contralateral to the facial atrophy (Eadie et al., 1963; Brain, 1969; Kumar et al., 1971). Carotid angiograms (Johnson and Kennedy, 1969), cerebrospinal fluid examinations (Hickman and Sheils, 1964), neostigmine tests (Merritt et al., 1937), erythrocyte sedimentation rate, and LE preparations (Hickman and Sheils, 1964) have been normal in the few reported cases where they have been done. In one case, electromyography (EMG) was normal (Hickman and Sheils, 1964). In another (Johnson and Kennedy, 1969), the EMG was normal in the atrophic facial muscles, but there was electrical silence in the tongue on the involved side. Johnson and Kennedy (1969) also noted that EMGs of paretic extraocular muscles in this disease have failed to demonstrate a neurogenic or myogenic process. The reported 
TABLE 3

NEUROPATHOLOGICAL OBSERVATIONS IN PROGRESSIVE FACIAL HEMIATROPHY

\begin{tabular}{|c|c|c|}
\hline Neuropathological observations & $\begin{array}{l}\text { Cases } \\
\text { (no.) }\end{array}$ & References \\
\hline $\begin{array}{l}\text { Neuritic-encephalitic } \\
\text { 1. Inflammation of cervical } \\
\text { sympathetic ganglia } \\
2 \text { Proliferative interstitial } \\
\text { neuritis of fifth nerve } \\
\text { 3. Focal encephalitis }\end{array}$ & $\begin{array}{l}3 \\
2 \\
1\end{array}$ & $\begin{array}{l}\text { Bruning (1923), Kroll } \\
\text { (1929), Stieff (1933) } \\
\text { Mendel (1883), Loebl } \\
\text { and Wiesel (1904) } \\
\text { Wartenberg (1945) }\end{array}$ \\
\hline Ventricular dilatation & 5 & Eadie et al. (1963) \\
\hline $\begin{array}{l}\text { Cerebrocerebellar calcification } \\
\text { Most likely calcified } \\
\text { haemangiomata }\end{array}$ & 3 & $\begin{array}{l}\text { Merritt et al. (1937), } \\
\text { Eadie et al. (1963) }\end{array}$ \\
\hline $\begin{array}{l}\text { Experimental cervical sympathectomy } \\
\text { Severe facial wasting and loss of } \\
\text { subcutaneous fat }\end{array}$ & & $\begin{array}{l}\text { Moss and Crikelair } \\
\text { (1959) }\end{array}$ \\
\hline Cerebellar atrophy, Purkinje cell loss & 1 & This report \\
\hline
\end{tabular}

pathological changes in facial hemiatrophy have been varied. Biopsy findings from affected face and limbs have revealed inconstant osteoporosis, inflammation, fibrosis, and vasculitis in the subcutaneous fat and deep layers of the skin (Osborne, 1922; Hickman and Sheils, 1964; Ashley et al., 1965). Such changes have been variously interpreted and in one patient (Hickman and Sheils, 1964) were suggestive of dermatomyositis. Johnson and Kennedy (1969) reported findings in biopsies of the temporal and gastrocnemius muscles but found no abnormality of muscle. Our own muscle biopsy findings examined by histochemical techniques and electron microscopy, revealed entirely normal muscle fascicles and a normal distribution and size of type I and type II muscle fibres. The extensive hemiatrophy must be assumed due to loss of subcutaneous tissue, in agreement with previous authors (Knight and Moore, 1959).

Neuropathological observations in progressive facial hemiatrophy have also been variable (see Table 3 for summary). Such pathological findings as have been reported include inflammatory conditions of the meninges and/or cranial nerves with a single reported case of focal encephalitis by Wartenberg (1945). Eadie et al. (1963) demonstrated ventricular dilatation in five cases and cerebrocerebellar calcification (thought to be in angiomatous malformations) has been reported in three cases (Eadie et al., 1963; Merritt et al., 1937). Our own findings re- $\frac{\mathrm{C}}{6}$ vealed no evidence of an encephalitic process but $T$ confirmed the presence of cerebellar atrophy? with loss of Purkinje cells, increased Bergman gliosis, mild atrophy of the molecular layer and patchy granular cell loss. Moreover, the cerebel-: lar biopsy revealed the presence of a meningeal microangiomatous malformation most suggest- $\bar{C}$ ive of a small arteriovenous malformation. The $\frac{\bar{\sigma}}{\overline{\bar{\sigma}}}$ results of long-term cultures of cerebral and $\frac{\bar{\rho}}{\vec{\Phi}}$ cerebellar tissue are not known at this time.

Cerebellar atrophy is very unusual in pro-ळ gressive facial hemiatrophy, and prompts the $\vec{\circ}$ report of this case. Although cerebellar degeneration has been reported in patients receiving large $\omega$ amounts of diphenylhydantoin (Utterback, 1958; Hofmann, 1958; Kokenge et al., 1965; Selhorstọ et al., 1972), we think it most unlikely that this is the cause of the cerebellar atrophy in our 0 patient because of the marked asymmetry cau용 ing a significant shift to the left of the fourtho ventricle.

The cause of progressive facial hemiatrophy 용 $\overrightarrow{0}$ unknown. Several authors (Archambault ando Fromm, 1932; Wartenberg, 1945; Banks anfi Sugar, 1963) have concluded that the disease results from hyper- or hypoactivity of the sympe thetic nervous system. They note the occasional reports of Horner's syndrome or mydriasis, and point to cases of this disease occurring after tuberculous infection of the lung apex or surgical removal of the cervical nodes with possible injury to the cervical sympathetic chain. Our $\stackrel{\circ}{\varnothing}$ patient has left pulmonary fibrosis. This was first seen on a chest film at 17 years of age. The only응 earlier chest film, at age 5 years, was normal. Moss and Crickelair (1959) performed unilateralo sympathectomy in 1 month old rats and facial hemiatrophy subsequently occurred in all. The most constant change was a marked decrease in $\overline{0}$ the amount of subcutaneous fat. Epithelium, muscle, dermal fibrous connective tissue, vessels, $\delta$ glandular and osseous tissue were all histo- $₹$

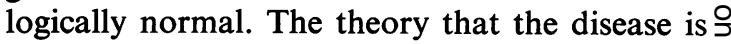
due to an abnormality of the sympathetic ner- $\frac{D}{0}$ vous system is unconvincing. Patients with Horner's syndrome almost never have facial o hemiatrophy. Horner's syndrome in its entirety N is rather a rarity in progressive facial hemi- N atrophy (Walsh, 1939). The widespread involve- 
ment of many tissues and organs and the multiple areas of neurological dysfunction suggest rather that symptoms of sympathetic dysfunction are but one manifestation of a multisystem disease. Nor have the pathological reports consistently shown abnormalities in the sympathetic system.

Some have considered the disease hereditary, but familial cases, though reported, are rare. Others have suggested local facial trauma as aetiologically important, but Rogers (1964) has pointed out that no case has ever been reported in a boxer. Wolff (1929) considered this to be a trophic disorder of central nervous system function of which the facial changes were only a part. Another theory implicates an abnormality of the trigeminal nerve, but many of the neurological and systemic abnormalities are beyond the innervation of this nerve. Others (Wartenberg, 1945) have suspected an infectious aetiology.

Several have felt that facial hemiatrophy was related to scleroderma and Hickman and Sheils (1964), whose patient showed inflammatory subcutaneous and muscle lesions, positive Latex test, and increased serum gamma globulin, suggested that the disease has an immunological basis.

Crikelair et al. (1962) found abnormally acute basilar skull angles, ranging from 95 to 114 degrees in five of six patients with progressive facial hemiatrophy and suggested the possibility of an underlying neurocranial malformation as the cause of this disease. In our patient the basilar angle was 133 degrees, which is normal.

Another possibility is that this disease is due to an unusual, perhaps a 'slow' virus. Nellhaus (1970) reported the case of a 4 year old girl with a six month history of left facial vitiligo and greying of the hair, aphasia, right hemiparesis, mental deterioration, and right hemiconvulsions. There was no fever or nuchal rigidity. Spinal fluid showed a normal cell count, moderately elevated protein and gamma globulin. Pneumoencephalography revealed left cerebral atrophy. A brain biopsy suggested viral encephalitis. Viral studies were negative, but the brain specimen was not inoculated into primates. He suggested the fascinating possibility of a similarity between the postulated virus in his case and the virus which causes discolouration in tulips.

\section{REFERENCES}

Archambault, L., and Fromm, N. K. (1932). Progressive facial hemiatrophy. Archives of Neurology and Psychiatry, 27, 529-584.

Ashley, F. L., Rees, T. D., Ballantyne, D. L., Jr, Galloway, D., Machida, R., Grazer, F., McConnell, D. V., Edgington, T., and Kiskadden, W. (1965). An injection technique for the treatment of facial hemiatrophy. Plastic and Reconstructive Surgery, 35, 640-648.

Banks, T. L., and Sugar, H. S. (1963). Ocular manifestations of facial hemiatrophy. Sinai Hospital Detroit Bulletin, 11, 83-88.

Brain, Lord, and Walton, J. N. (1969). Brain's Diseases of the Nervous System, 7th edn. Oxford University Press: London.

Brüning, F. (1923). Die trophische Funktion der sympathischen Nerven. Klinische Wochenschrift, 2, 67-69.

Crikelair, G. F., Moss, M. L., and Khuri, A. (1962). Facial hemiatrophy. Plastic and Reconstructive Surgery, 29, 5-13.

Dawson, T. A. J., and Beare, J. M. (1966). Facial hemiatrophy (Parry-Romberg syndrome). British Journal of Dermatology, 78, 545-546.

Eadie, M. J., Sutherland, J. M., and Tyrer, J. H. (1963). The clinical features of hemifacial atrophy. Medical Journal of Australia, 50 (2), 177-180.

Hickman, J. W., and Sheils, W. S. (1964). Progressive facial hemiatrophy. Archives of Internal Medicine, 113, 716-720.

Hofmann, W. W. (1958). Cerebellar lesions after parenteral dilantin administration. Neurology (Minneap.), 8, 210-214.

Johnson, R. V., and Kennedy, W. R. (1969). Progressive facial hemiatrophy (Parry-Romberg syndrome). American Journal of Ophthalmology, 67, 561-564.

Knight, J. S., and Moore, J. R. (1959). Hemiatrophy of the face. Oral Surgery, Oral Medicine, and Oral Pathology, 12, 585-590.

Kokenge, R., Kutt, H., and McDowell, F. (1965). Neurological sequelae following Dilantin overdose in a patient and in experimental animals. Neurology (Minneap.), 15, 823-829.

Kroll, M. (1929). Die Neuropathologischen Syndrome. Springer: Berlin.

Kumar, P., Agrawal, B. V., Singh, N. P., Mukerji, M., and Edoliya, T. N. (1971). Progressive right hemifacial atrophy with contralateral cerebral hemiatrophy. Journal of the Association of Physicians of India, 19, 595-597.

Loebl, H., and Wiesel, J. (1904). Zur Klinik und Anatomie der Hemiatrophia facialis progressiva. Deutsche Zeitschrift für Nervenheilkunde, 27, 355-374.

Mendel, E. (1883). Ein Fall von halbseitiger Gesichtsatrophie. Neurologisches Centralblatt, 2, 268-270.

Merritt, K. K., Faber, H. K., and Bruch, H. (1937). Progressive facial hemiatrophy. Journal of Pediatrics, 10, 374 395.

Moss, M. L., and Crikelair, G. F. (1959). Progressive facial hemiatrophy following cervical sympathectomy in the rat. Archives of Oral Biolog v, 1, 254-258.

Moura, R. A. (1963). Progressive facial hemiatrophia. American Journal of Ophthalmology, 55, 635-639.

Nellhaus, G. (1970). Acquired unilateral vitiligo and poliosis of the head and subacute encephalitis with partial recovery. Neurology (Minneap.), 20, 965-974.

Osborne, E. D. (1922). Morphea associated with hemiatrophy of the face. Archives of Dermatology and Syphylis, 6, 27-34.

Rogers, B. O. (1964). Progressive facial hemiatrophy (Romberg's disease). In Third International Congress of Plastic Surgeons, Washington, 1963. Transactions, pp. 681-689. International Congress Series No. 66. Excerpta Medica: Amsterdam. 
Selhorst, J. B., Kaufman, B., and Horwitz, S. J. (1972). Diphenylhydantoin-induced cerebellar degeneration. Archives of Neurology (Chic.), 27, 453-455.

Stief, A. (1933). Über einen Fall von Hemiatrophie des Gesichtes mit Sektionbefund. Zeitschrift für die gesamte Neurologie und Psychiatrie, 147, 573-593.

Sugar, H. S., and Banks, T. L. (1964). Fuchs' heterochromic cyclitis associated with facial hemiatrophy (scleroderma en coup de sabre). American Journal of Ophthalmology, 57, 627-632.

Utterback, R. A. (1958). Parenchymatous cerebellar degeneration complicating diphenylhydantoin (Dilantin) therapy.
(Abstract.) Archives of Neurology and Psychiatry (Chic.), 80, 180-181.

Walsh, F. B. (1939). Facial hemiatrophy. American Journal of Ophthalmology, 22, 1-10.

Walsh, F. B., and Hoyt, W. F. (1969). Clinical NeuroOphthalmology, 3rd edn. Williams and Wilkins: Baltimore.

Wartenberg, R. (1925). Zur Klinik und Pathogenese der Hemitrophia faciei progressiva. Archiv für Psychiatrie und Nervenkrankheiten, 74, 602-630.

Wartenberg, R. (1945). Progressive facial hemiatrophy. Archives of Neurology and Psychiatry (Chic.), 54, 75-96.

Wolff, H. G. (1929). Progressive facial hemiatrophy. Journal of Nervous and Mental Diseases, 69, 140-144. 